\title{
Detecção de locos de características quantitativas nos cromossomos 9, 10 e 11 de suínos
}

\author{
Ana Paula Gomes Pinto ${ }^{1}$, Paulo Sávio Lopes ${ }^{2}$, Marcos Soares Lopes ${ }^{3}$, Miguel Inácio Silva Filho ${ }^{4}$, \\ Katiene Régia Silva Sousa ${ }^{1}$, Paulo Luiz Souza Carneiro ${ }^{5}$, Simone Eliza Facioni Guimarães ${ }^{2}$ \\ 1 Programa de Pós-graduação em Zootecnia - UFV. \\ 2 Universidade Federal de Viçosa, Viçosa, Minas Gerais, CEP: 36570-000. Pesquisadores participantes do INCT - Ciência Animal. \\ Departamento de Zootecnia. \\ ${ }^{3}$ Graduação em Zootecnia - UFV. \\ 4 Programa de Pós-graduação em Genética e Melhoramento - UFV. \\ ${ }^{5}$ Departamento de Ciências Biológicas, Universidade Estadual do Sudoeste da Bahia, Jequié, Bahia, CEP: 45200-000.
}

RESUMO - Objetivou-se com este estudo mapear locos de características quantitativas (QTL) nos cromossomos 9, 10 e 11 de suínos (Sus scrofa) e associar seus efeitos em características de carcaça, cortes de carcaça, órgãos e vísceras, desempenho e qualidade de carne. Utilizaram-se amostras de DNA de animais pertencentes a uma população F2, oriunda do cruzamento entre machos da raça Piau e fêmeas Landrace $\times$ Large White $\times$ Pietrain. Um total de 13 locos microssatélites foi utilizado na construção dos mapas de ligação da população atual. As análises de associação foram feitas utilizando-se mapeamento de intervalo por regressão para detecção de QTL. Identificaram-se associações significativas, em nível cromossômico, entre regiões do cromossomo 9 e as características peso total do carré e peso do lombo. No cromossomo 10, foram detectados três QTL significativos para espessura de toucinho na linha dorso-lombar entre a última e a penúltima vértebra lombar, peso de pulmão e índice de vermelho e um QTL significativo, no nível genômico, para peso de fígado. No cromossomo 11, foi detectada apenas uma associação significativa, em nível cromossômico, relacionada à espessura de toucinho imediatamente após a última costela, a 6,5 cm da linha dorso-lombar. As informações dos QTL significativos encontrados são importantes para estudos futuros, como o mapeamento fino e a identificação de genes, que ajudem no melhor entendimento da fisiologia e das características de produção de suínos.

Palavras-chave: análise genômica, população F2, produção de suínos, microssatélites

\section{Detection of quantitative trait loci on chromosomes 9,10 and 11 of swines}

\begin{abstract}
The objective of this study was to map quantitative trait loci (QTL) in chromosomes 9, 10 and 11 of swines (Sus scrofa) and to associate their effects on traits of carcass, carcass cuts, organs and guts, performance and meat quality. Samples of DNA of animals from a F2 population originated from crosses between Piau breed males and Landrace $\times$ Large White $\times$ Pietrain females were used. A total of 13 microsatellite loci were used to build link maps of the present population. Analyses of association were done using mapping of intervals by regression for QTL detection. Significant association were identified at the cromossomic level between cromossome 9 regions and total (bone-in) loin weight and boneless loin weight. On cromossom 10, three significant QTL were detected for midline backfat thickness immediately between the last and penultimate the last rib, lung weight and redness and a significant QTL at the genomic level for weight of liver. On chromosome 11, only one significant association was detected at cromosomic level related for backfat thickness immediately after the last rib at $6.5 \mathrm{~cm}$ from the midline. Information from significant QTL found here are important for future studies as fine mapping and gene identification, which help on a better understanding of physiology and characteristics of swine production.
\end{abstract}

Key Words: F2 population, genomic analysis, microsatellites, pig production

\section{Introdução}

A eficiência de um programa de melhoramento genético depende diretamente da precisão com que os indivíduos são avaliados. Segundo Martinez \& Machado (2002), em muitas situações, o fenótipo não é uma indicação precisa do genótipo, pois características produtivas dependem da variação alélica em grande número de locos, e a expressão gênica desses locos é altamente afetada por fatores de ambiente. Assim, é de grande valia a seleção de indivíduos baseada na associação entre dados fenotípicos e informações genômicas (Seleção Assistida por Marcadores - MAS). 
Por definição, Quantitative Trait Loci (QTL) são regiões cromossômicas relacionadas à variação das características quantitativas. A hipótese empregada para a localização de um QTL é de que marcadores moleculares polimórficos estejam próximos e suficientemente ligados ao QTL, de forma que, na maioria da progênie de um indivíduo heterozigoto para o marcador, seja possível associar a variação na característica quantitativa de interesse com o genótipo do marcador, que será indicativo do genótipo do QTL. A frequência como ocorre a recombinação causada por crossing-over nos cromossomos dos indivíduos parentais permitirá estabelecer a estimativa da distância genética entre o marcador e o QTL. Entre os marcadores mais utilizados, estão os microssatélites (Mota et al., 2000).

Objetivou-se com este estudo detectar e avaliar o efeito de QTL localizados nos cromossomos 9 (SSC9), 10 (SSC10) e 11 (SSC11) para características de desempenho, carcaça, órgãos e vísceras, cortes de carcaça e qualidade de carne em uma população $\mathrm{F} 2$ de suínos formada a partir do cruzamento divergente entre machos da raça naturalizada Piau e fêmeas Landrace $\times$ Large White $\times$ Pietrain.

\section{Material e Métodos}

A formação da população experimental e a coleta dos dados fenotípicos foram realizadas na Universidade Federal de Viçosa (UFV) no período de novembro de 1998 a julho de 2001, como descrito por Paixão (2008) e Silva (2009). Foi construída uma população F2, composta por 714 animais, proveniente do cruzamento entre dois varrões da raça naturalizada brasileira Piau e 18 fêmeas de linhagem desenvolvida na UFV pelo acasalamento de animais Landrace $\times$ Large White $\times$ Pietrain selecionados para desempenho.

Foram mensuradas as características de desempenho, de carcaça, dos cortes de carcaça, qualidade de carne e órgãos internos (Tabelas 1, 2, 3 e 4).

A extração do DNA das amostras de sangue e a análise genotípica dos animais parentais F1 e F2 foram conduzidas no Laboratório de Biotecnologia Animal do Departamento de Zootecnia da UFV. Foram utilizados 13 pares de primers de marcadores microssatélites distribuídos nos cromossomos 9,10 e 11 , pois esses cromossomos apresentam grande número de genes e locos gênicos mapeados, como o gene da Miogenina (MYOG) e da Apolipoproteína A1 (APOA1), presentes no SSC9; o gene do Fator Beta 2 de Transformação de Crescimento, presente no SSC10, e o gene da Peptidase B (PEPB), presente no SSC11, entre outros.

As amplificações foram feitas em termocicladores MJ Research PTC 100-96 ${ }^{\circledR}$. As reações foram constituídas de água bidestilada, Taq DNA polimerase $1 \mathrm{U}$, Tampão IB 10X, dNTPs $0,2 \mathrm{mM}$, primer foward e reverse $0,2 \mathrm{mM}$ cada um, 25 ng de DNA genômico por reação e volume final de $15 \mu \mathrm{L}$. O DNA amplificado foi visualizado em gel de poliacrilamida 8\% para verificação do tamanho e da intensidade das bandas e a existência de bandas inespecíficas. Após a confirmação das amplificações, o escoreamento dos fragmentos amplificados foi feito utilizando-se o software GenScan (Applied Biosystems) por meio de sequenciador automático ABI PRISM 310.

Tabela 1 - Características de desempenho em uma população F2 de suínos

\begin{tabular}{lccc}
\hline Característica & $\begin{array}{c}\text { Número de } \\
\text { observações }\end{array}$ & Média & $\begin{array}{c}\text { Desvio- } \\
\text { padrão }\end{array}$ \\
\hline Número de tetas & 800 & 13,167 & 1,280 \\
Peso ao nascer (kg) & 800 & 1,200 & 0,282 \\
Peso aos 21 dias (kg) & 665 & 4,874 & 1,180 \\
Peso aos 42 dias (kg) & 665 & 8,245 & 1,988 \\
Peso aos 63 dias (kg) & 656 & 16,210 & 3,432 \\
Peso aos 77 dias (kg) & 602 & 21,423 & 4,381 \\
Peso aos 105 dias (kg) & 595 & 36,262 & 6,742 \\
Peso ao abate (kg) & 510 & 64,749 & 5,629 \\
Consumo de ração (kg) & 598 & 39,806 & 8,355 \\
Ganho de peso diário (kg) & 591 & 0,530 & 0,139 \\
Conversão alimentar (kg/kg) & 591 & 2,799 & 0,650 \\
Idade ao abate (dias) & 521 & 147,942 & 10,616 \\
\hline
\end{tabular}

Tabela 2 - Características de carcaça, órgãos internos e vísceras em uma população F2 de suínos

\begin{tabular}{|c|c|c|c|}
\hline Característica & $\begin{array}{l}\text { Número de } \\
\text { bservações }\end{array}$ & Média & $\begin{array}{l}\text { Desvio- } \\
\text { padrão }\end{array}$ \\
\hline $\begin{array}{l}\text { Rendimento de carcaça } \\
\text { com cabeça e pés (\%) }\end{array}$ & 518 & 81,990 & 2,243 \\
\hline $\begin{array}{l}\text { Comprimento de carcaça } \\
\text { pelo método brasileiro } \\
\text { de classificação de carcaça }(\mathrm{cm})\end{array}$ & 531 & 86,064 & 4,173 \\
\hline $\begin{array}{l}\text { Comprimento de carcaça } \\
\text { pelo método americano }(\mathrm{cm})\end{array}$ & 531 & 71,709 & 3,874 \\
\hline $\begin{array}{l}\text { Maior espessura de toucinho } \\
\text { na região da copa }(\mathrm{mm})\end{array}$ & 532 & 40,496 & 5,578 \\
\hline $\begin{array}{l}\text { Espessura de toucinho } \\
\text { imediatamente após a última } \\
\text { costela (mm) }\end{array}$ & 532 & 19,889 & 4,825 \\
\hline $\begin{array}{l}\text { Espessura de toucinho entre } \\
\text { a última e a penúltima vértebra } \\
\text { lombar }(\mathrm{mm})\end{array}$ & 531 & 28,678 & 6,110 \\
\hline $\begin{array}{l}\text { Menor espessura de toucinho } \\
\text { acima da última vértebra lombar (mm) }\end{array}$ & m) & 23,510 & 6,225 \\
\hline $\begin{array}{l}\text { Espessura de toucinho imediatamente } \\
\text { após a última costela }(\mathrm{mm})\end{array}$ & e 531 & 16,951 & 3,835 \\
\hline Espessura do bacon (mm) & 528 & 25,138 & 6,965 \\
\hline Profundidade do lombo (mm) & 486 & 43,981 & 5,040 \\
\hline Área de olho-de-lombo $\left(\mathrm{cm}^{2}\right)$ & 494 & 26,281 & 4,059 \\
\hline Peso do pulmão (kg) & 530 & 0,456 & 0,088 \\
\hline Peso do coração (kg) & 532 & 0,236 & 0,030 \\
\hline Peso do figado (kg) & 526 & 1,267 & 0,155 \\
\hline Peso do baço (kg) & 526 & 0,092 & 0,019 \\
\hline Peso do rim (kg) & 536 & 0,127 & 0,019 \\
\hline $\begin{array}{l}\text { Comprimento total do } \\
\text { intestino delgado }(\mathrm{m})\end{array}$ & 539 & 18,424 & 1,856 \\
\hline
\end{tabular}


As informações acerca das heterozigosidades esperada (He) e observada (Ho) e o conteúdo de informação polimórfica (PIC) dos marcadores microssatélites foram estimados utilizando-se o programa CERVUS versão 2.0 (Marshall et al., 1998).

Para a construção do mapa de ligação dos SSC9, SSC10 e SSC11, utilizou-se o programa CRIMAP, versão 2.4 (Green et al., 1990). Os dados de genótipo, fenótipo e o mapa de ligação gerado foram submetidos ao programa GridQTL (Seaton et al., 2006) para detecção de QTL. No modelo estatístico utilizado, assumiu-se que o QTL é dialélico e com alelos alternativos fixados em cada raça parental. A probabilidade de cada indivíduo F2 apresentar cada um dos três genótipos do QTL é calculada conforme o genótipo dos marcadores, a intervalos de $1 \mathrm{cM}$ ao longo do cromossomo. Essas probabilidades são usadas para se fazer a regressão das características nos coeficientes aditivos e de dominância do QTL em estudo, para cada animal, como descrito por Haley et al. (1994).

A determinação dos limiares de significância cromossômica ( $\alpha=0,05$ e $\alpha=0,01)$ foi feita com o auxílio do programa GridQTL, com testes de 10.000 permutações (Churchill \& Doerge, 1994). Onível de significância genômico foi obtido utilizando a correção de Bonferroni, que consiste em determinar o valor do nível de significância no cromossomo que proporcionará o nível de significância conjunto desejado; ou seja, o nível de significância desejado que deverá ser proporcional à contribuição de cada cromossomo para o comprimento total do genoma autossômico, como sugerido por De Koning et al. (1999).

A probabilidade foi calculada pela seguinte equação:

$P($ genômico $)=1-\left(1-P(\text { cromossômico })^{1 / r}\right.$

em que $\mathbf{r}$ é a contribuição de um cromossomo, que é obtida dividindo-se o comprimento do cromossomo (ou segmento) testado pelo comprimento do genoma autossômico. O intervalo de confiança a 95\% (IC95\%) para a localização do QTL foi obtido usando a aproximação do Qui-quadrado $\left(\chi^{2}\right)$, conforme descrito por Pérez-Enciso et al. (2000).

O seguinte modelo estatístico foi ajustado aos dados: $\mathrm{Y}_{\mathrm{ijkl}}=\mathrm{S}_{\mathrm{i}}+\mathrm{L}_{\mathrm{j}}+\mathrm{H}_{\mathrm{k}}+\left(\mathrm{C}_{\mathrm{ijkl}}-\overline{\mathrm{C}}\right) \mathrm{b}+\mathrm{c}_{\mathrm{a}} \mathrm{a}+\mathrm{c}_{\mathrm{d}} \mathrm{d}+\mathrm{e}_{\mathrm{ijkl}}$ em que: $Y_{i j k l}=$ fenótipo; $S_{i}=$ efeito fixo do sexo $i, i=1$ (macho), 2 (fêmea); $L_{j}$ = efeito fixo do lote ou da época de parição $j, j=1$, 2, 3, 4, 5; $H_{k}=$ efeito fixo do genótipo do gene do halotano $k, k=1(\mathrm{NN}), 2(\mathrm{Nn}) ;\left(\mathrm{C}_{\mathrm{ijk}}-\overline{\mathrm{C}}\right) \mathrm{b}=$ ajustamento para as covariáveis.

Para características de desempenho, as covariáveis utilizadas foram: tamanho de leitegada ao nascimento para peso ao nascimento; tamanho de leitegada ao desmame para peso aos 21, 42, 63, 77 e 105 dias e peso ao abate; peso aos 77 dias para consumo de ração, ganho de peso diário e conversão alimentar. Como covariáveis, foram considerados o peso da carcaça ao abate, para as características de carcaça; o peso da banda direita resfriada, para as características de corte de carcaça; e a idade ao abate, para as características de qualidade de carne.

O genótipo para o gene halotano foi incluído como efeito fixo, uma vez que Band et al. (2005a,b) observaram não apenas a presença da mutação $\mathrm{Hal}_{1843}$ nesta população, mas também seus efeitos $(\mathrm{P}<0,05)$ sobre as características de desempenho, carcaça e qualidade de carne.

A fração aditiva da variância fenotípica $\left(\hat{h}^{2}{ }\right)$ da F2 explicada por determinado QTL foi computada conforme descrito por Pérez-Enciso et al. (2000), assumindo-se que alelos alternativos estão fixados em cada raça, $\hat{\mathrm{h}}^{2} \mathrm{Q}=\mathrm{a}^{2} / 2 \hat{\sigma}^{2}{ }^{2}$, de modo que $\hat{\sigma}_{\mathrm{y}}$ é o desvio-padrão residual considerando os efeitos fixos e as co-variáveis, exceto o QTL; e " $a$ " é o efeito aditivo, gerado pelo programa GridQTL. Os valores de aditividade $\left(\mathrm{C}_{\mathrm{a}}\right)$ e de dominância $\left(\mathrm{C}_{\mathrm{d}}\right)$ são funções das probabilidades condicionais do QTL

Tabela 3 - Peso dos cortes de carcaça de uma população F2 de suínos

\begin{tabular}{|c|c|c|c|}
\hline Característica & $\begin{array}{l}\text { Número de } \\
\text { observações }\end{array}$ & Média & $\begin{array}{l}\text { Desvio- } \\
\text { padrão }\end{array}$ \\
\hline Pernil & 536 & 7,282 & 0,862 \\
\hline $\begin{array}{l}\text { Peso do pernil sem pele e } \\
\text { sem capa de gordura }\end{array}$ & $\begin{array}{l}538 \\
538\end{array}$ & $\begin{array}{l}5,010 \\
2 \quad 334\end{array}$ & 0,650 \\
\hline Сора & 538 & 2,334 & 0,354 \\
\hline $\begin{array}{l}\text { Copa sem pele e sem capa } \\
\text { de gordura }\end{array}$ & 537 & 1,682 & 0,272 \\
\hline Paleta & 538 & 4,865 & 0,642 \\
\hline $\begin{array}{l}\text { Paleta sem pele e sem capa } \\
\text { de gordura }\end{array}$ & 538 & 2,708 & 0,408 \\
\hline Carré & 538 & 3,487 & 0,533 \\
\hline Lombo & 537 & 1,028 & 0,202 \\
\hline Bacon & 534 & 2,690 & 0,467 \\
\hline Costelas & 538 & 1,524 & 0,252 \\
\hline Papada & 538 & 0,709 & 0,210 \\
\hline Filezinho & 538 & 0,221 & 0,041 \\
\hline Banha-rama & 538 & 0,460 & 0,167 \\
\hline
\end{tabular}

Tabela 4 - Características de qualidade da carne avaliadas em uma população F2 de suínos

\begin{tabular}{lccc}
\hline Característica & $\begin{array}{c}\text { Número de } \\
\text { observações }\end{array}$ & Média & $\begin{array}{c}\text { Desvio- } \\
\text { padrão }\end{array}$ \\
\hline pH 45 minutos pós-abate & 410 & 6,530 & 0,284 \\
pH 24 horas pós-abate & 501 & 5,720 & 0,184 \\
Luminosidade & 452 & 45,076 & 2,016 \\
Índice de vermelho & 446 & 0,666 & 0,631 \\
Índice de amarelo & 453 & 6,605 & 0,649 \\
Gordura intramuscular (\%) & 456 & 1,546 & 0,667 \\
Perdas por gotejamento (\%) & 501 & 3,221 & 1,741 \\
Perdas por cozimento (\%) & 503 & 32,575 & 2,672 \\
Maciez objetiva (kg/cm $\left.{ }^{2}\right)$ & 411 & 5511,630 & 972,335 \\
Perda total (\%) & 499 & 35,747 & 3,488 \\
Índice de saturação & 455 & 6,687 & 0,541 \\
\hline
\end{tabular}

R. Bras. Zootec., v.39, n.10, p.2174-2181, 2010 
considerando o genótipo dos locos e são calculados da seguinte forma:

$$
\begin{aligned}
& \mathrm{C}_{\mathrm{a}}=\mathrm{P}(\mathrm{QQ} / \mathrm{Mi})-\mathrm{P}(\mathrm{qq} / \mathrm{Mi}) \\
& C_{d}=P(Q q / M i)
\end{aligned}
$$

em que: $\mathrm{P}(\mathrm{QQ})=$ probabilidade de os alelos do $\mathrm{QTL}$ serem homozigotos com origem da raça naturalizada Piau; $\mathrm{P}(\mathrm{qq})$ = probabilidade de os alelos do QTL serem homozigotos com origem da linhagem Landrace $\times$ Large White $\times$ Pietrain; $\mathrm{P}(\mathrm{Qq})=$ probabilidade de os alelos do QTL serem heterozigotos.

\section{Resultados e Discussão}

Os locos de microssatélite analisados (Tabela 5) forneceram informações que justificam o seu uso em estudos de QTL na população, pois a aplicabilidade de um marcador possui relação direta com seu grau de polimorfismo, uma vez que, quanto maior a variabilidade genética do marcador, maior o conteúdo de informação acerca da segregação gênica na população.

Segundo Ott (1992), um marcador é considerado altamente polimórfico quando apresenta heterozigosidade observada superior a 0,70. Assim, os marcadores SW1848, SW940 e S0295 podem ser considerados altamente polimórficos. Em relação à heterozigosidade esperada, com exceção de SW2116 e SW173, todos os locos apresentaram valores superiores a 0,50 indicando elevada variabilidade genética. Segundo a classificação de Botstein et al. (1980), marcadores com valores de PIC superiores a 0,50 são considerados muito informativos, com valores entre $0,25 \mathrm{e}$ 0,50 , mediamente informativos e com valores inferiores a 0,25 , pouco informativos. Assim, os locos analisados podem ser classificados em dois grupos: altamente informativos (SW21, SW1848, SW940, S0295, SW830, SW2008, S0071, S0230, SW66) e medianamente informativos (SY3, SW2116, SW1894, SW173).

O comprimento total dos mapas construídos foi de 158 cM; 126 cM e 111 cM, respectivamente, para os cromossomos 9, 10 e 11 , superior em 21,75; 124,60 e 26,75\% aos mapas do USDA-MARC (Rohrer et al., 1996), mas sem alteração na ordem dos marcadores. As diferenças encontradas justificam-se pelo fato de que nos estudos não se utilizou o mesmo conjunto de marcadores e as populações utilizadas são diferentes. A diversidade genética dentro dessas populações estaria influenciando a taxa de recombinação (meiose), uma vez que o programa CRIMAP utiliza esta informação como base para construir os mapas de ligação, o que refletiria em variações no comprimento dos mapas para as populações.

Optou-se por utilizar o mapa do SSC10 gerado pelo USDA-MARC (Rohrer et al., 1996) para as análises de QTL devido à grande diferença de comprimento entre esse mapa, caracterizado como consenso, e o mapa gerado a partir dos dados da população. Essa diferença se deve ao fato de os marcadores utilizados apresentarem distorção de segregação na população em estudo. Segundo Carneiro \& Vieira (2002), a ausência do padrão Mendeliano, chamada distorção de segregação, é causada pelo efeito de amostragem ou viabilidade diferencial de gametas. Liu (2005), ao realizar uma varredura genômica a partir de uma população F2 Duroc $\times$ Pietrain, também detectou distorção de segregação no cromossomo 10.

Foram identificados QTL para características de cortes de carcaça, no SSC9; para características de carcaça,

Tabela 5 - Heterozigosidade observada e esperada, conteúdo de informação polimórfica e posição, em centiMorgan, dos marcadores utilizados no mapeamento

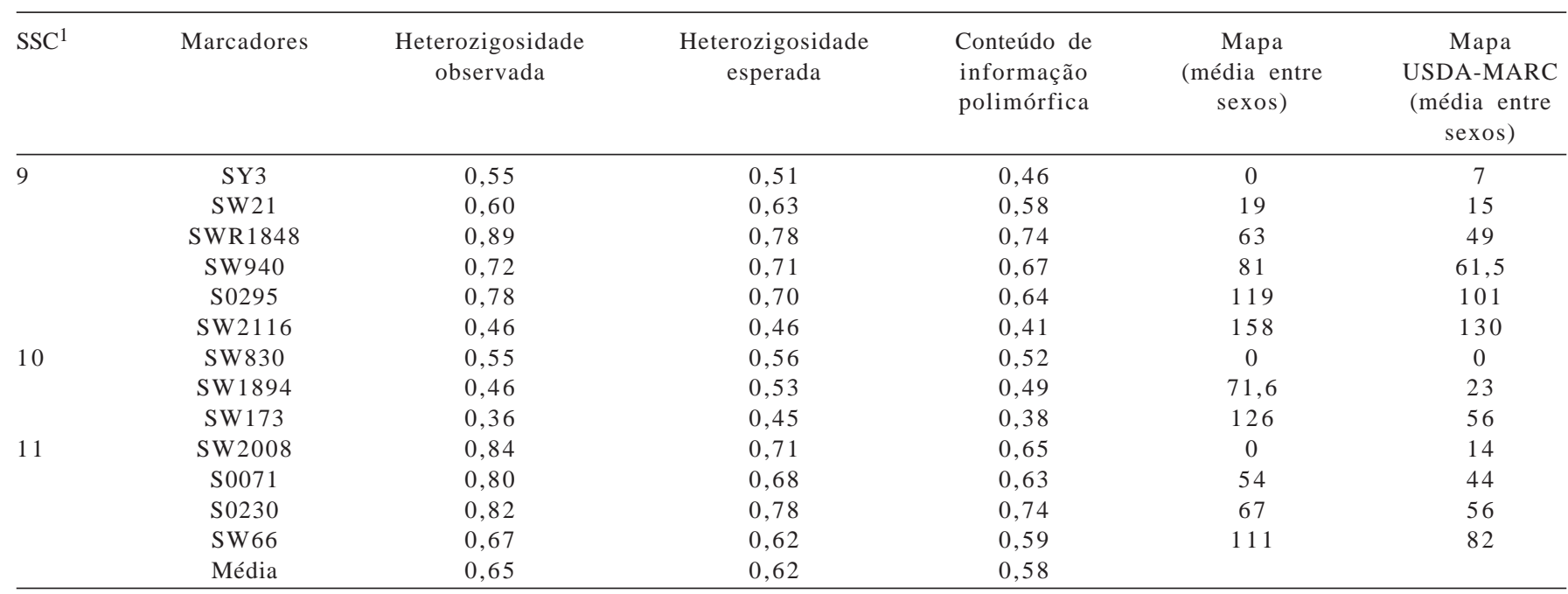


órgãos e vísceras e qualidade de carne no SSC10; e para características de carcaça no SSC11 (Tabela 6). Não foram encontrados QTL significativos para características de desempenho em nenhum dos cromossomos estudados. No entanto, existem relatos da presença de QTL significativos para ganho de peso diário (Cepica et al., 2003; Kim et al., 2006), peso ao abate (Cepica et al., 2003) e conversão alimentar (Cepica et al., 2003) no SSC9; peso ao abate (Dragos-Wendrich et al., 2003a) no SSC10 e consumo de ração (Dragos-Wendrich et al., 2003b) no SSC11.

No SSC9 foram detectados QTL para peso total do carré e peso do lombo (Figura 1). Para peso de carré, o QTL atingiu o limiar de significância de 5\% no nível cromossômico e foi localizado a 64 cM (IC95\%=20-65 cM), respondendo por 1,91\% da variação fenotípica da característica. Para peso de lombo, o loco de característica quantitativa atingiu o limiar de significância de $1 \%$ no nível cromossômico e foi localizado a 73 cM (IC95\%=63-105 cM), respondendo por $4,49 \%$ da variação fenotípica da característica. Os alelos da linhagem Landrace $\times$ Large White $\times$ Pietrain culminaram no aumento do valor fenotípico de ambas as características nessa população. É necessária a inclusão de marcadores adicionais para melhor delimitar o intervalo de confiança da região de ambos os QTL.

O intervalo de confiança do QTL para peso total do carré encontra-se dentro do intervalo de confiança do QTL para peso de lombo (Figura 1), o que pode ser explicado pela forte correlação entre essas características, já que o corte denominado carré abrange todo o dorso do corpo do animal, inclusive as costelas do lombo e o próprio lombo.

Não foram encontrados relatos na literatura consultada de QTL para peso do lombo no SSC9, entretanto, Rohrer et al. (2005) detectaram QTL significativo para área de olho de lombo (IC=50-53cM) em região próxima à do QTL encontrado para peso de lombo. Edwards et al. (2008), em uma varredura genômica em uma população F2 derivada do cruzamento entre as raças Duroc e Pietrain, utilizando 124 marcadores microssatélites, não encontraram associação significativa entre características de corte de carcaça e o SSC9. Não foram encontrados relatos na literatura consultada de QTL para peso do carré no cromossomo 9.

Assim como no trabalho de Cepica et al. (2003), neste estudo não foram encontradas associações entre a região próxima ao gene da miogenina (9q21-q26) e variações fenotípicas em características de crescimento, apesar da relação entre esse gene e o processo de miogênese. No entanto, Te Pas et al. (1999) estudaram os efeitos fenotípicos do gene da miogenina a partir de suínos da raça Yorkshire pertencentes a linhas comerciais e atribuíram 4\% da variância fenotípica nas características peso ao nascimento, à taxa de crescimento e ao peso de carcaça e 5,8\% na variância para deposição de carne magra ao loco MYOG.

No cromossomo 10, foram detectados QTL para espessura de toucinho entre a última e a penúltima vértebra lombar, na linha dorso-lombar; peso de pulmão; peso de fígado (Figura 2) e índice de vermelho (Figura 3). O QTL para

Tabela 6 - Estatísticas F máximas (Fmax), posições, estimativas dos efeitos aditivos e de dominância para as características significativas nos cromossomos estudados

\begin{tabular}{|c|c|c|c|c|c|c|}
\hline SSC & Característica & $\mathrm{F}_{\max }$ & $\begin{array}{l}\text { Posição, cM } \\
\text { (intervalo de } \\
\text { confiança) }\end{array}$ & $\begin{array}{c}\text { Efeito } \\
\text { aditivo } \\
\text { (erro-padrão) }\end{array}$ & $\begin{array}{c}\text { Efeito de } \\
\text { dominância } \\
\text { (erro-padrão) }\end{array}$ & $\mathrm{h}_{\mathrm{Q}}^{2}(\%)$ \\
\hline 10 & $\begin{array}{c}\text { Carcaça } \\
\text { Espessura de } \\
\text { toucinho entre a } \\
\text { última e a } \\
\text { penúltima }\end{array}$ & & & & & \\
\hline 11 & $\begin{array}{l}\text { vertébra lombar } \\
\text { Espessura de } \\
\text { toucinho } \\
\text { imediatamente } \\
\text { após a última }\end{array}$ & $5,02 *$ & $56(38-57)$ & $1,16(0,37)$ & $0,40 \quad(0,65)$ & 2,49 \\
\hline & $\begin{array}{c}\text { costela } \\
\text { Cortes de carcaça }\end{array}$ & $4,78^{*}$ & $0(0-23)$ & $0,45(0,26)$ & $1,09(0,40)$ & 0,97 \\
\hline 9 & Peso do carré & $6,31 *$ & $64(47-76)$ & $-0,06(0,03)$ & $-0,11(0,04)$ & 1,91 \\
\hline 9 & $\begin{array}{l}\text { Peso do lombo } \\
\text { Órgãos e vísceras }\end{array}$ & $7,70 * *$ & 73 (63-105) & $-0,04(0,01)$ & $-0,03 \quad(0,02)$ & 4,49 \\
\hline 10 & Peso do pulmão & $7,35 * *$ & $31(24-47)$ & $-0,03 \quad(0,00)$ & $-0,03 \quad(0,02)$ & 6,27 \\
\hline 10 & $\begin{array}{l}\text { Peso do fígado } \\
\text { Qualidade de carne }\end{array}$ & $8,88 * * *$ & $27(24-39)$ & $-0,05(0,01)$ & $-0,08 \quad(0,03)$ & 5,50 \\
\hline 10 & Índice de vermelho & $6,53 * *$ & $48(34-57)$ & $-0,21 \quad(0,06)$ & $-0,23(0,12)$ & 4,23 \\
\hline
\end{tabular}


espessura de toucinho entre a última e a penúltima vértebra lombar foi significativo a 5\% ao nível cromossômico, na posição de 56 cM (IC95\%=38-57 cM), explicando apenas 2,5\% da variação fenotípica da característica. Esse QTL possui efeito aditivo, assim, atribuiu-se aos alelos da raça Piau o aumento na média fenotípica da característica na população. Isso pode ser explicado pelo fato de a raça Piau ter como característica maior deposição de gordura em comparação às linhas comerciais. O loco de característica quantitativa para peso do pulmão foi significativo a $1 \%$ ao nível cromossômico, estálocalizado a 31 cM(IC95\%=24-47cM) e responde por $6,3 \%$ da variação fenotípica da característica. O loco de característica quantitativa para peso do fígado foi significativo a 5\% ao nível genômico, localizou-se na posição de 27 cM (IC95\%=24-39 cM) e explica 5,5\% da variação fenotípica. É atribuído aos alelos da linhagem Landrace $\times$ Large White $\times$ Pietrain, o aumento do peso do fígado e do pulmão na população.

Não foram encontrados na literatura consultada relatos da presença de QTL para peso do pulmão no SSC 10. Essa diferença entre resultados pode ter sido ocasionada pela utilização de populações com composições genéticas diferentes entre os estudos. O alelo de interesse do QTL detectado neste trabalho para peso de pulmão pode estar segregando apenas no cruzamento entre machos Piau e fêmeas Landrace $\times$ Large White Pietrain ou pode não estar em fase de desequilíbrio de ligação com os marcadores utilizados nos outros estudos.

O loco de característica quantitativa para espessura de toucinho entre a última e a penúltima vértebra lombar (Tabela 5) também não foi reportado na literatura consultada. A região onde essa associação foi encontrada tem sido associada a características de qualidade de carne (Markljung et al., 2008; Van Wijk et al., 2006).

Dragos-Wendrich et al. (2003a) detectaram associação significativa entre a região proximal do SSC10 e o peso de fígado segregando em famílias F2 derivadas dos cruzamentos Porco Selvagem Europeu $\times$ Meishan e Meishan $\times$ Pietrain . No entanto, no mesmo trabalho, esse QTL não foi detectado no cruzamento Porco Selvagem Europeu $\times$ Pietrain. Já Quintanilla et al. (2002) detectaram QTL, a 27 cM, para espessura média de toucinho ( $\mathrm{mm}$ ) na $17^{\underline{a} \text { a }}$ semana de idade quando analisaram características de crescimento e deposição de gordura em uma população F2 Large White $\times$ Meishan.

O loco de característica quantitativa para índice de vermelho atingiu o limiar de significância de $1 \%$ no nível cromossômico e foi localizado a 48 cM (IC95\%=34-57 cM) no SSC10, respondendo por 4,23\% da variação fenotípica da característica. Esse loco de característica quantitativa é bastante relevante, uma vez que a cor da carne in natura é um dos fatores de qualidade mais importantes para o consumidor no momento da compra (Souza, 2006) e está associada ao frescor e à boa qualidade do produto. Segundo Souza (2006), a cor da carne reflete a quantidade e o estado químico do seu principal pigmento, a mioglobina. Os alelos da linhagem Landrace $\times$ Large White $\times$ Pietrain causaram 0 aumento do índice de vermelho na população. Esse fato não era esperado, pois existe correlação positiva entre (índice de vermelho e porcentagem de gordura intramuscular. Além disso, a raça Piau apresenta maior deposição de gordura em comparação à linhagem Landrace $\times$ Large White $\times$ Pietrain . Provavelmente, essa característica é controlada por outras regiões localizadas em outros cromossomos.

Van Wijk et al. (2006) obtiveram resultado semelhante ao do presente estudo ao detectar QTL significativo para índice de vermelho do lombo a 42 cM, segregando em uma população derivada do cruzamento entre raças comerciais.

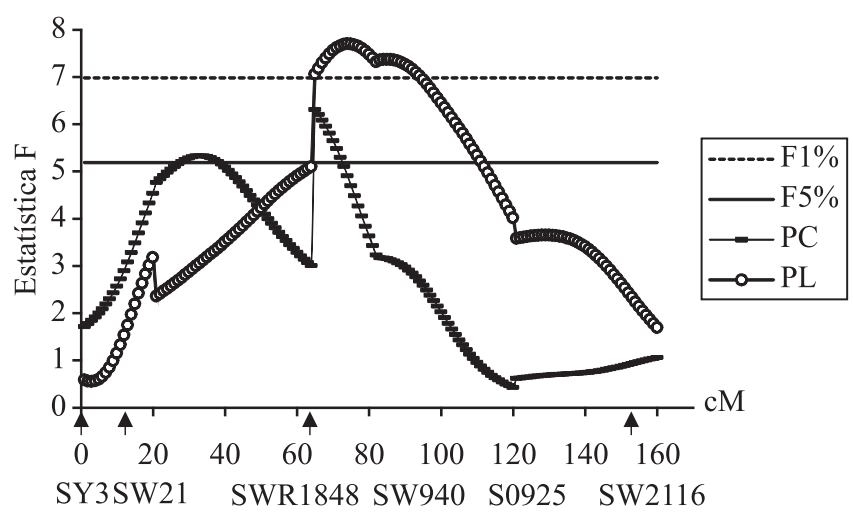

Linhas horizontais indicam níveis de significância.

Figura 1 - Perfil de QTL ao longo do SSC9 para as características peso total do carré (PL) e peso do lombo (PL).

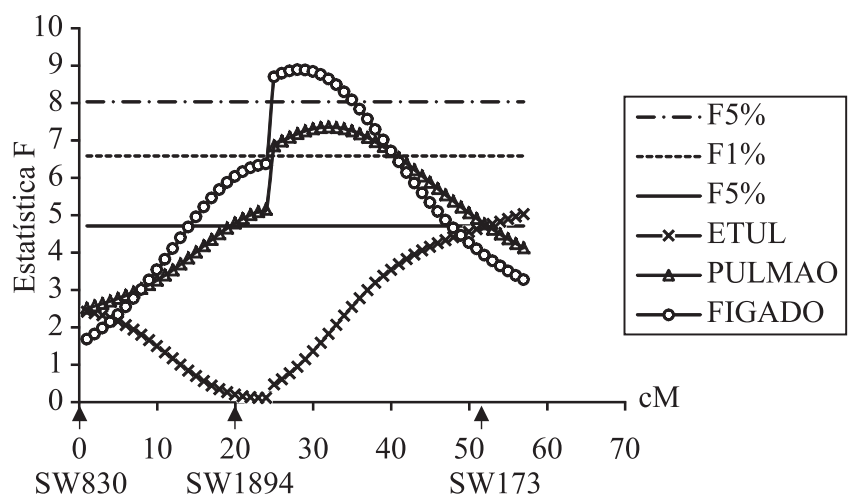

Linhas horizontais indicam níveis de significância.

Figura 2 - Perfil de QTL para espessura de toucinho na linha dorso-lombar, entre a última e a penúltima vértebra lombar (ETUL), peso de pulmão (PULMAO) e peso de fígado (FIGADO), ao longo do SSC10. 
Markljung et al. (2008) encontraram QTL significativo para esta característica segregando em uma família resultante do cruzamento entre as raças Hampshire e Landrace, a 122 cM no cromossomo 10. Entretanto, Ovilo et al. (2002) realizaram uma varredura genômica, com o auxílio de 92 marcadores microssatélites em uma população F2 Ibérico × Landrace e não encontraram QTL para índice de vermelho no cromossomo 10, mas notaram associações significativas entre essa característica e regiões dos cromossomos 4 e 8 .

Foi detectada associação significativa a 5\% no nível cromossômico entre uma região do SSC11 e a característica espessura de toucinho medida imediatamente após a última costela, a 6,5 cm da linha dorso-lombar (Figura 4). Esse QTL explica $0,97 \%$ da variação fenotípica da característica e localiza-se na posição de 0 cM (IC95\% = 0-12 cM), sendo atribuído aos alelos da raça Piau o aumento na média

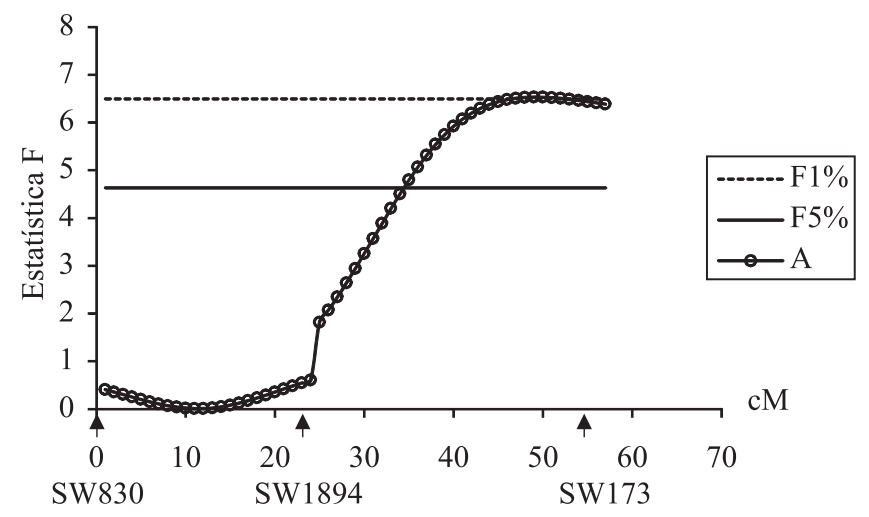

Linhas horizontais indicam níveis de significância.

Figura 3 - Perfil de QTL para a característica índice de vermelho (A) no cromossomo SSC10.

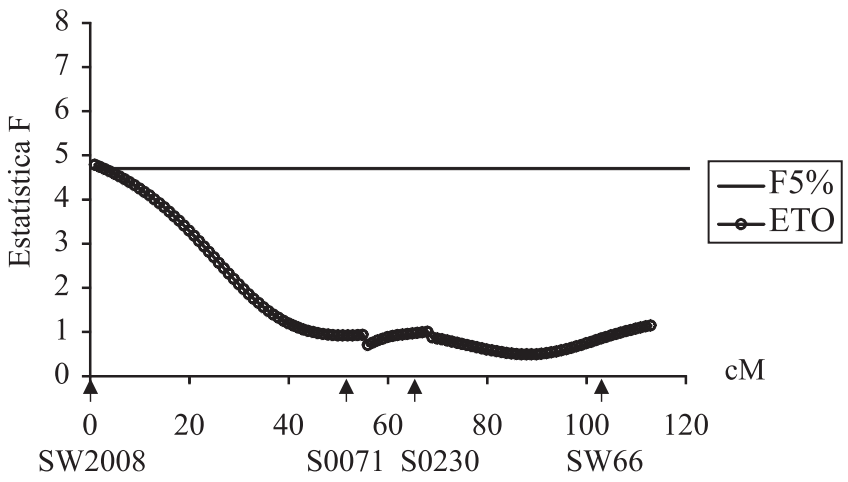

Linhas horizontais indicam os níveis de significância.

Figura 4 - Perfil de QTL para a característica espessura de toucinho imediatamente após a última costela, a 6,5 cm da linha dorso-lombar (ETO), ao longo do cromossomo SSC11. fenotípica da característica na população. Esse loco de característica quantitativa também foi detectado por Edwards et al. (2008) em uma população F2 Duroc $\times$ Pietrain. Nessa região, Milan et al. (2002) detectaram QTL significativos ao nível cromossômico para peso de toucinho (kg) e para porcentagem de toucinho + deposição de gordura na copa em uma população F2 derivada do cruzamento entre as raças Meishan e Large White.

Em contraste aos resultados encontrados neste estudo (Tabela 6), há relatos na literatura consultada da presença de QTL para área de olho-de-lombo (Liu et al., 2005), espessura de toucinho na última costela e na última vértebra lombar (Roher, 2000), peso de fígado (Cepica et al., 2003), peso de paleta (Milan et al., 2002) no SSC9; porcentagem de gordura intramuscular (Dekkers et al., 2003; Edwards et al., 2008) no SSC10; peso de fígado (Dragos-Wendrich et al., 2003b) e área de olho-de-lombo (Rohrer \& Keele, 1998) no SSC11.

\section{Conclusões}

Nos cromossomos 9, 10 e 11 de suínos de uma população F2 formada a partir do cruzamento entre machos da raça naturalizada Piau e fêmeas comerciais (Landrace $x$ Large White $\times$ Pietrain) há locos de características quantitativas atuando sobre as características de carcaça, órgãos e vísceras, cortes de carcaça e qualidade de carne. O mapeamento fino dessas regiões será necessário para melhor entendimento do efeito de cada QTL e a possível detecção de genes candidatos.

\section{Referências}

BAND, G.O.; GUIMARÃES, S.E.F.; LOPES, P.S. et al. Relationship between the porcine stress syndrome gene and pork quality trait in F2 pigs resulting from divergent crosses. Genetics and Molecular Biology, v.8, n.1, p.88-91, 2005a.

BAND, G.O.; GUIMARÃES, S.E.F.; LOPES, P.S. et al. Relationship between the porcine stress Syndrome gene and carcass and performance trait in F2 pigs resulting from divergent crosses. Genetics and Molecular Biology, v.28, n.1, p.92-96, 2005b.

BOTSTEIN, D.; WHITE, R.L.; SKOLMICK, H. et al. Construction of a genetic linkage map in man using restriction fragment length polymorphism. American Journal of Human Genetics, v.32, p.314-331, 1980.

CARNEIRO, M.S.; VIEIRA, M.L.C. Mapas genéticos em plantas. Bragantia, v.61, n.2, p.89-100, 2002.

CEPICA, S.; SCHROFFEL JR, J.; STRATIL, A. et al. Linkage and QTL mapping for Sus scrofa chromosome 9. Journal of Animal Breeding and Genetics, v.120, n.1, p.74-81, 2003.

CHURCHILL, G.A.; DOERGE, R.W. Empirical threshold values for quantitative trait mapping. Genetics, v.138, p.963-971, 1994.

DEKKERS, J.; THOMSEN, H.; LEE, H. et al. Detection of imprinted QTL in the Berkshire $x$ Yorkshire cross. In: NATIONAL SWINE IMPROVEMENT FEDERATION CONFERENCE AND 
ANNUAl MEeting, 28., 2003, Iowa. Proceedings... Iowa: NSIF, 2002. (CD-ROM).

DE KONING, D.J.; JANSS, L.L.G.; RATTINK, A.P. et al. Detection of quantitative trait loci for backfat thickness and intramuscular fat content in pigs (Sus scrofa). Genetics, v.152, p.1679-1690, 1999.

DRAGOS-WENDRICH, M.; MOSER, G.; BARTENSCHLAGER, H. et al. Linkage and QTL mapping for Sus scrofa chromosome 10. Journal of Animal Breeding and Genetics, v.120, n.1, p.82-88, 2003a.

DRAGOS-WENDRICH, M.; MOSER, G.; BARTENSCHLAGER, H. et al. Linkage and QTL mapping for Sus scrofa chromosome 11. Journal of Animal Breeding and Genetics, v.120, n.1, p.89-94, 2003b.

EDWARDS, D.B.; ERNST, C.W.; RANEY, N.E. et al. Quantitative trait locus mapping in an F2 Duroc x Pietrain resource population: II. Carcass and meat quality traits. Journal of Animal Science, v.86, p.254-266, 2008.

GREEN, P.; FALLS, K.; CROOKS, S. [1990]. Documentation for CRIMAP, St. Louis, Mo.: Washington Univ. School of Medicine. Disponível em: <http://linkage.rockefeller.edu/soft/crimap> Acesso em: 1/1/2007.

HALEY, C.S.; KNOTT, S.A.; ELSEN, J.M. Mapping quantitative trait loci in crosses between outbred lines using least squares. Genetics, v.36, p.1195-1207, 1994.

KIM, C.W.; HONG, Y.H.; YUN, S. et al. Use of microssatellite markers to detect quantitative trait loci in yorkshire pigs. The Journal of Reproduction and Development, v.52, p.229-237, 2006.

LIU, G. Detection and characterization of QTL in a porcine Duroc Pietrain resource population. 2005. 129f. Thesis (PhD in Molecular and Quantitative Genetics) - Universität Bonn, Bonn, Germany.

MARSHALL, T.C.; SLATE, J.; KRUUK, L.E.B. et al. Statistical confidence for likelihood-based paternity inference in natural populations. Molecular Ecology, v.7, p.639-655, 1998.

MARKLJUNG, E.; BRAUNSCHWEIG, M.H.; KARLSKOVMORTENSEN, P. et al. Genome-wide identification of quantitative trait loci in a cross between Hampshire and Landrace II: meat quality traits. BMC Genetics, v.9, p.22, 2008.

MARTINEZ, M.L.; MACHADO, M.A. Programa genoma brasileiro de bovinos e suas perspectivas de aplicações práticas. In: SIMPÓSIO NACIONAL DE MELHORAMENTO ANIMAL, 4., 2002, Campo Grande. Anais... Campo Grande: SBMA, 2002.

MILAN, D.; BIDANEL, J.P.; IANNUCCELLI, N. et al. Detection of quantitative trait loci for carcass composition traits in pigs. Genetics Selection Evolution, v.34, n.6, p.705-28, 2002.

MOTA, A.F.; MARTINEZ, M.L.; COUTINHO, L.L. Localização de locos gênicos de características quantitativas (QTLs) em gado de leite - premissas e estratégias. Multiciência (ASSER), v.4, n.1, p.18-37, 2000

OTT, J. Strategies for characterization highly polymorphic markers in human gene mapping. American Journal of Human Genetics, v.51, p.283-290, 1992.
OVILO, C.; CLOP, A.; NOGUERA, J.L. et al. Quantitative trait locus mapping for meat quality traits in an Iberian $\mathrm{x}$ Landrace F2 pig population. Journal of Animal Science, v.80, p.2801-2808, 2002.

PAIXÃO, D.M.; GUIMARÃES, S.E.F., SILVA FILHO, M.I. et al Detecção de locos de características quantitativas nos cromossomos 16, 17 e 18 de suínos. Revista Brasileira de Zootecnia, v.37, n.10, p.1781-1787, 2008.

PÉREZ-ENCISO, M.; CLOP, A.; NOGUERA, J.L. et al. A QTL on pig chromosome 4 affects fatty acid metabolism: evidence from a Iberian by Landrace intercross. Journal of Animal Science, v.78, p.2525-2531, 2000.

QUINTANILLA, R.; MILAN, D.; BIDANEL, J.P. A further look at quantitative trait loci affecting growth and fatness in a cross between Meishan and Large White pig populations. Genetics Selection Evolution, v.34, p.193-210, 2002.

ROHRER, G.A.; ALEXANDER, L.J.; HU, Z. et al. A comprehensive Map of the Porcine Genome. Genome Research, v.6, p.371-391, 1996.

ROHRER, G.A.; KEELE, J.W. Identification of quantitative trait loci affecting carcass composition in swine: II. Muscling and wholesale product yield traits. Journal of Animal Science, v.76, p.2255-2262, 1998.

ROHRER, G.A. Identification of quantitative trait loci affecting birth characters and accumulation of backfat and weight in a Meishan-White composite resource population. Journal of Animal Science, v.78, p.2547-2553, 2000.

ROHRER, G.A.; THALLMAN, R.M.; SHACKELFORD, S.D. et al. A genome scan for loci affecting pork quality in a DurocLandrace F2 population. Animal Genetics, v.37, p.17-27, 2005.

SEATON, G.; HERNANDEZ J.; GRUNCHEC J.A. et al. GridQTL: a grid portal for QTL mapping of compute intensive datasets. In: WORLD CONGRESS ON GENETICS APPLIED TO LIVESTOCK PRODUCTION, 8., 2006, Belo Horizonte. Anais... Belo Horizonte: SBMA, 2006. (CD-ROM).

SILVA, K.M.; GUIMARÃES, S.E.F.; LOPES, P.S. Mapeamento de locos de características quantitativas para desempenho no cromossomo 4 de suínos. Revista Brasileira de Zootecnia, v.38, n.3, p.474-479, 2009.

SOUZA, H.B.A. Parâmetros físicos e sensoriais utilizados para avaliação de qualidade da carne de frango. In: SEMINÁRIO INTERNACIONAL DE AVES E SUÍNOS, 5., 2006 , Florianópolis. Anais Eletrônicos... Florianópolis: AVESUI, 2006. (CD-ROM).

TE PAS, M.F.; SOUMILLION, A.; HARDERS, F.L. et al. Influences of myogenin genotypes on birth weight, growth rate, carcass weight, backfat thickness and lean weight of pigs. Journal of Animal Science, v.77, p.2352-2356, 1999.

VAN WIJK, H.J.; DIBBITS, B.; BARON, E.E. et al. Identification of quantitative trait loci for carcass composition and pork quality traits in a commercial finishing cross. Journal of Animal Science, v.84, p.789-799, 2006. 